\title{
Seasonal variability of the oceanic upper layer and its modulation of biological cycles in the Canary Island region
}

\author{
C. Troupin ${ }^{a, *}$, P. Sangrà ${ }^{b}$ and J. Arístegui ${ }^{b}$ \\ ${ }^{a}$ Université de Liège, GeoHydrodynamics and Environment Research (B5a), B400o Liège, Belgium \\ ${ }^{\mathrm{b}}$ Facultad de Ciencias del Mar, Universidad de Las Palmas de Gran Canaria, 35017 Las Palmas de Gran Canaria, Spain
}

\begin{abstract}
The Canary Island region is rich in mesoscale phenomena that affect cycles of physical and biological processes. A $1 \mathrm{D}$ version of the Regional Oceanic Modeling System (ROMS) is used south of the Gran Canaria Island to simulate seasonal climatologies of these cycles. The model is forced with monthly air-sea fluxes averaged from 1993 to 2002 and initialized with mean in situ profiles of temperature, salinity, oxygen and nitrate concentrations. The K-Profile Parameterization (KPP) mixed-layer submodel is compared with other submodels using idealized numerical experiments. When forced with realistic air-sea fluxes, the model correctly reproduces the annual cycle of temperature (mixed layer depth), with minimum surface values of $18^{\circ} \mathrm{C}$ (maximal depth $>105 \mathrm{~m}$ ) in February during convective mixing resulting from a negative heat flux. Maximum temperatures above $23^{\circ} \mathrm{C}($ minimal depth $<20 \mathrm{~m}$ ) are simulated from September to October after strong summer heating and a decrease in Trade Winds intensity. A simple ecosystem model is coupled to the physical model, which provides simulated biological cycles that are in agreement with regional observations. A phytoplankton bloom develops in late winter, driven by the injection of new nutrients into the euphotic layer. Chlorophyll has a deep maximum fluctuating around $100 \mathrm{~m}$ with concentrations around $1 \mathrm{mg} C h l_{a} \mathrm{~m}^{-3}$, while surface values are low (around $0.1 \mathrm{mg} \mathrm{Chl} \mathrm{m}^{-3}$ ) during most of the year. The physical and biological model results are validated by comparisons with data from regional campaigns, climatological fields and time-series from the ESTOC station.
\end{abstract}

Key words: Canary Islands, Mixed layer depth, ROMS 1D bio-physical model, biological cycles, KPP model, NPZD model, Latitude $27.5^{\circ} \mathrm{N}$, longitude $15.5^{\circ} \mathrm{W}$

PACS: 92.60.Aa, 92.10.Lq, 92.60.Cc, 92.05.Fg

\section{Introduction}

The Canary Island Archipelago is composed of seven islands located in the passage of the cool, southwestward Canary Current $(\mathrm{CC})$, considered as the eastern boundary of the North Atlantic subtropical gyre. The study of physical and biological cycles in this region is an important topic considering the numerous physical processes that influence these cycles.

Since the 1990's, many studies were carried out in the Canary Island area in order to examine interactions between physical and biological processes (e.g. Arístegui et al., 1994, 1997; Arístegui and Montero, 2005; Barton et al., 2004; Pelegrí et al., 2005a,b). Along with these in situ studies, time-series data were acquired through mooring stations, such as the European Station for Time-Series in the Ocean,

\footnotetext{
* Corresponding author.

Email address: ctroupin@ulg.ac.be (C. Troupin).
}

Canary Islands (ESTOC, Fig. 1), located $100 \mathrm{~km}$ north of Gran Canaria (Neuer et al., 2007). Satellite imagery from the region was used to confirm these observations (Barton et al., 2001; Davenport et al., 2002).

Braun (1976) carried out a survey 5 miles off Tenerife from 1971 to 1972 between the ocean surface and 1200 meters. Low levels of nutrients along with a clear seasonal variation of phytoplankton were reported, confirming the oligotrophic conditions of Canary Island waters (e.g. De León and Braun, 1973; Arístegui et al., 1997).

Summer is characterized by a sharp seasonal thermocline that prevents the injection of nutrients into the euphotic zone, resulting in low phytoplankton concentrations. Maximal phytoplankton concentrations appear in late winter under the effect of convective mixing and thermocline erosion, which make nutrients available for phytoplankton. These high concentrations were also observed by Hernández-León et al. (1984) in southern Canary waters, Hernández-León et al. (1984) on the southeastern shelf of the Gran Canaria 
Island, and Arístegui et al. (2001) in coastal waters east of Gran Canaria.

Despite interest in understanding biological cycles in this area, only a few coupled physical-biological models have been developed. Zielinski et al. (2002) used a onedimensional model in order to test different parameterizations of the photosynthetically active radiation (PAR) at ESTOC station. Although their model produced realistic results for temperature and chlorophyll concentration, there was no validation of the mixed layer depth model, which is of crucial importance for the modulation of biochemical cycles.

Bahamón and Cruzado (2003) compared the NW Mediterranean and NE Atlantic using a one-dimensional model, but their results for the physical variables do not represent accurately the seasonal cycles in the second system. They showed stratification starting in April, which is too early, and two maxima for the phytoplankton. The first maximum was in winter and the second in fall, a situation that is more typical for higher latitudes.

The first objective of the present work was to simulate the seasonal cycle of the upper oceanic layer similar to what was observed in the Canary Island region. To this end, a one-dimensional physical-biological coupled model forced with recently developed climatologies for air-sea fluxes (e.g. OAFluxes for heat, Tab. 2) and initialized with characteristic conditions of this particular region was used.

A point south of Gran Canaria (Fig. 1) was selected for model implementation because the biological properties in this area were more frequently sampled. The model implementation site is located in the transitional zone between the upwelling rich waters and the oligotrophic interior ocean. It may be affected by mesoscale variability introduced by the Archipelago, but these effects were filtered out in the climatological observations. Because of the recognition that dynamics of the ocean upper layer are fundamental for the modulation of biochemical fluxes, special attention was paid to the mixed layer seasonal cycle, making comparisons with other physical model outputs and with available measurements.

A second objective was the establishment of a seasonal climatology of biogeochemical properties of the oceanic upper layer, which will help in implementing a threedimensional physical-biogeochemical model currently under development (Mason et al., 2008b,a), as is a coupled larvae model focused on the same region (Brochier et al., 2008).

To achieve these goals, the work is divided into five parts: the first is the description of the different components (physics, biology, mixed layer) of the model, as well as the assumptions behind them (Section 2). Next details of the model setup are described by outlining forcing and initialization conditions (Section 3), as these are key to generating realistic solutions. The model behavior is tested in idealized experiments (Section 4) and the resulting annual fields are presented (Section 5) and validated (Section 6).

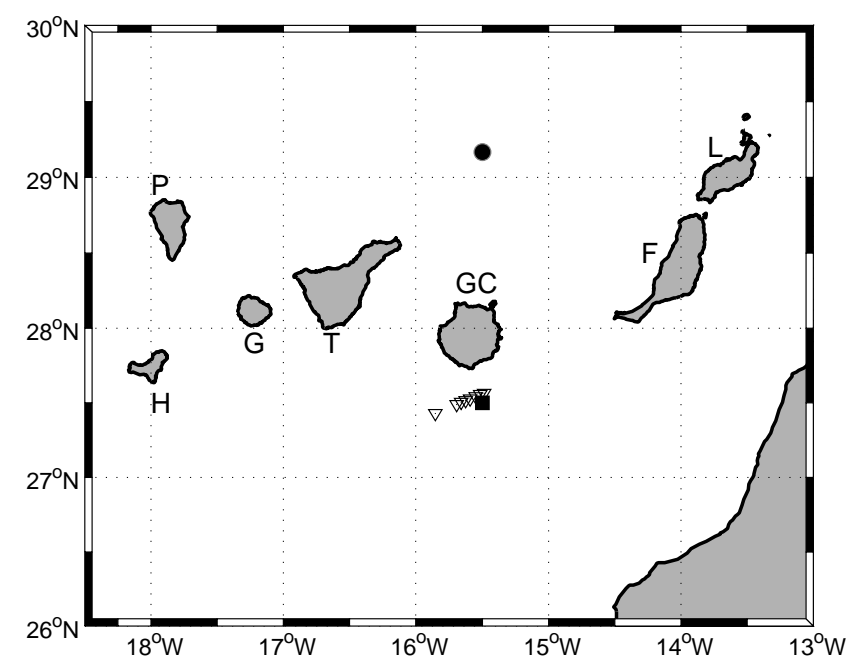

Fig. 1. The Canary Archipelago: $\mathrm{P}=$ La Palma, $\mathrm{H}=\mathrm{El}$ Hierro, $\mathrm{G}=$ La Gomera, $\mathrm{T}=$ Tenerife, GC $=$ Gran Canaria, $\mathrm{F}=$ Fuerteventura, $\mathrm{L}=$ Lanzarote. The region of interest is located south to Gran Canaria (square). Circle denotes ESTOC station and triangles are the locations of the profiles used in the initialization.

\section{Model description}

Simulations were carried out with the one-dimensional version of ROMS (Regional Ocean Modeling System, Shchepetkin and McWilliams, 2005); the mixing closure sub-model, treatments of vertical advection and diffusion are compatible between the $3 \mathrm{D}$ and the $1 \mathrm{D}$ model. A stretched vertical coordinate system provides an increased resolution near the surface boundary layer (Penven, 2006).

\subsection{Hydrodynamics model}

The hydrodynamics model computes velocity components $(u$ and $v$ ), temperature $(T)$ and salinity $(S)$. Density is derived from the state equation of Jackett and McDougall (1995). Hydrostatic and $f$-plane approximations are made. Two important consequences arise from the use of a 1-D model:

(i) the vertical velocity is null everywhere: $w=0$,

(ii) advection is not modeled $(\mathbf{u} \cdot \boldsymbol{\nabla}) X=0$, with $\mathbf{u}$, the velocity vector, and $X$, any scalar variable.

Temperature and salinity are both relaxed toward their initial value with a relaxation time $\tau$ depending of the depth: $\tau=2+23 \exp (z / 100)$. This formula gives a value of $\tau$ about 5 years below $200 \mathrm{~m}$ and up to 25 years at the surface.

\subsection{Mixed layer model}

Small-scale processes are parametrized with the KProfile Parametrization (KPP, Large et al., 1994). With this scheme, the mixed-layer depth (MLD hereinafter) is defined as the depth $d$ at which the bulk Richardson number, which measures the ratio between stratification and shearing, equals a prescribed critical value: 


$$
\operatorname{Ri}_{b}(d)=\frac{\left[B_{r}-B(d)\right] d}{\left|\mathbf{V}_{r}-\mathbf{V}(d)\right|^{2}+V_{t}^{2}(d)}=\operatorname{Ri}_{c r}=0.3,
$$

where $B_{r}$ and $\mathbf{V}_{r}$ are estimates of the average buoyancy and velocity, respectively, and $V_{t} / h$ is the turbulent velocity shear.

When buoyancy forcing is stable, the boundary layer depth is taken as the minimum of the value computed according to Eq. (1), the Monin-Obukov length and the Ekman depth.

The KPP model enables to take into account mixing through salt fingering (warm salty water over cool fresh water), a typical process in regions with low precipitation and intense solar radiation.

\subsection{Ecosystem model}

The box model (Fig. 2) from Fasham et al. (1990) was designed to simulate annual cycles of plankton dynamics and nitrogen cycling in the upper oceanic layer. Nitrogen is generally considered as the limiting nutrient of primary production, hence its choice as central element of the biological model. The Fasham et al. (1990) model has been applied to numerous areas of the ocean (e.g. Sarmiento et al., 1993; Drange, 1996). The version implemented in ROMS is an evolution of this model (Gruber et al., 2006), which has also been applied to another transition zone (California).

It was chosen for its simplicity, according to the objective of getting mean seasonal cycles. Moreover, the model is compartmental, so that it permits the distinction between new production (driven by new nutrients, primarily nitrate, that originates from outside the euphotic zone) and regenerated production (driven by nitrogen recycled within the euphotic zone, mainly ammonium) (Dugdale and Goering, 1967). Bacteria were eliminated as an explicitly modeled state variable, and replaced with implicit parametrizations of remineralization processes (Gruber et al., 2006).

Biological variables are coupled to physics by an advection-diffusion-reaction equation and through temperature. The latter influences various production terms of the ecosystem model. This again emphasizes the need of a correct representation of temperature seasonal cycle.

The model is also forced by the photosynthetically available radiation (PAR), derived from the shortwave solar radiation (Fig. 3) according to the following steps (Frentzel, 2006):

(i) A linearly interpolated value is calculated for each time step.

(ii) A diurnal cycle for insulation is superimposed on the solar shortwave radiation. If the calculated surface radiation is negative, zero is used instead.

(iii) Starting from the top, the $P A R$ is calculated for each grid box according to

$$
\begin{aligned}
& P A R_{\jmath}= \\
& P A R_{\jmath+1} \exp \left\{\left(-0.5\left(k_{w}+k_{C h l a}[C h l a]_{\jmath}\right) \Delta z_{\jmath}\right\}\right.
\end{aligned}
$$

with $k_{w}$ and $k_{C h l a}$, the attenuation coefficients for water and chlorophyll (Tab. 1), [Chla] the chlorophyll concentration, $\Delta z$, the height of the vertical grid layer and $\jmath$ the cell index, from 1 at the bottom to $\mathrm{N}$ at the top.

As light abundance is an essential factor for primary production in pelagic systems, an accurate parametrization of its variation with depth is required. Zielinski et al. (2002) tested several $P A R$ parametrizations and showed that the light model has significant effects on the simulated distribution of chlorophyll, both in space and time. They recommend using a model with an increased value of the attenuation coefficient near the surface, due to absorption at larger wavelengths, and with a specific chlorophyll attenuation.

Model parameters for the fluxes between compartments (Tab. 1) are either based on measured values in the region, or are standard values. When no information was available for the region of interest, model prescribed values, originally adapted to California region, were used.

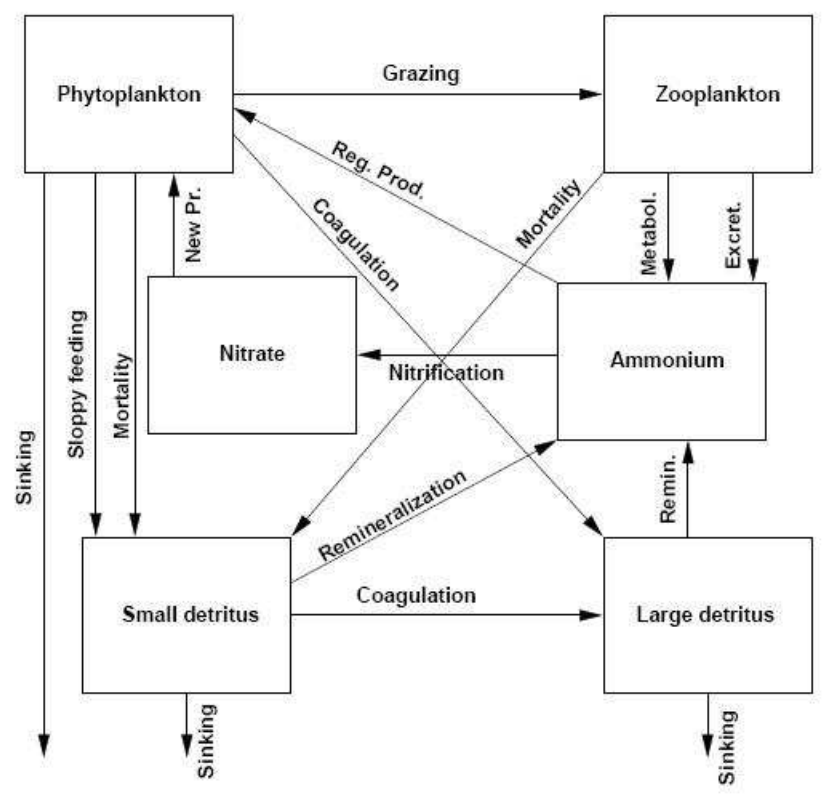

Fig. 2. Compartments and nitrogen fluxes of the biological model (reproduced from Frentzel (2006)).

\section{Simulations settings}

\subsection{Forcing}

The ROMS 1D is forced by heat fluxes, wind stress and freshwater flux. These fields were extracted from different data bases (Tab. 2) and monthly averaged values for the 1993-2002 period were computed at a location south of Gran Canaria $\left(27.5^{\circ} \mathrm{N}, 15.5^{\circ} \mathrm{W}\right)$. The choice of the 10-year averaged forcing fields was motivated by the desire to obtain a mean seasonal cycle. Shorter time scale processes are not the target of the study. 
Table 1

Parameters of the biological model: (1) Fasham et al. (1990), (2) Gruber et al. (2006), (3) Redfield (1934), (4) Zielinski et al. (2002), (5) Sarmiento et al. (1993), (6) Dadou et al. (2001); ( ) model default values.

\begin{tabular}{|c|c|c|c|c|}
\hline Parameter & Symbol & Values & Unit & Source \\
\hline Light attenuation due to sea water & $k_{w}$ & 0.04 & $m^{-1}$ & $(1,2)$ \\
\hline Light attenuation by chlorophyll a & $k_{C h l a}$ & 0.025 & $m^{2}(m g C h l a)^{-1}$ & $(2)$ \\
\hline Initial slope of the $P-I$ curve & $\alpha$ & 5.00 & $m g C\left(m g C h l a W m^{-2} d\right)^{-1}$ & $(\star)$ \\
\hline$C: N$ ratio for phytoplankton & $r_{C: N ; p h y t o}$ & 6.625 & $m \operatorname{Mol} C(m M o l N)^{-1}$ & $(3)$ \\
\hline Maximum cellular chlorophyll to $C$ Ratio & $\theta_{m}$ & 0.053 & $m g C h l a: m g C$ & $(2)$ \\
\hline Inverse half-saturation for phytoplankton $\mathrm{NO}_{3}$ uptake & $K_{N_{3}}$ & $1 / 0.5$ & $1 /\left(m M o l N m^{3}\right)$ & $(4)$ \\
\hline Inverse half-saturation for phytoplankton $\mathrm{NH}_{4}$ uptake & $K_{N H_{4}}$ & $1 / 0.1$ & $1 /\left(m M o l N m^{3}\right)$ & $(\star)$ \\
\hline Phytoplankton mortality to small detritus rate & $t_{\text {Pmort }}$ & 0.07 & $d^{-1}$ & $(5)$ \\
\hline Zooplankton-specific maximum grazing rate & $t_{Z g r a z e}$ & 0.75 & $d^{-1}$ & $(\star)$ \\
\hline Zooplankton assimilation efficiency & $A E$ & 0.75 & -- & $(2,4,6)$ \\
\hline Zooplankton gross growth efficiency & $G G E$ & 0.65 & -- & $(\star)$ \\
\hline Zooplankton half-saturation constant for ingestion & $Z_{P}$ & 1.00 & $m M o l N m^{3}$ & $(2)$ \\
\hline Zooplankton specific excretion rate & $t_{Z b m e t}$ & 0.10 & $d^{-1}$ & $(\star)$ \\
\hline Zooplankton quadratic mortality to detritus & $t_{Z m o r t}$ & 0.10 & $d^{-1}\left(m M o l N m^{3}\right)^{-1}$ & $(2)$ \\
\hline Small detrital breakdown to $\mathrm{NH}_{4}$ rate & $t_{S D r e m i n}$ & 0.1 & $d^{-1}$ & $(\star)$ \\
\hline Specific (Per unit Phyto $+S D e t$ ) aggregation rate & $t_{\text {coag }}$ & 0.005 & $\left(m M o l N m^{3}\right)^{-1} d^{-1}$ & $(2)$ \\
\hline Specific rate of large detritus recycling to $\mathrm{NH}_{4}$ & $t_{\text {LDremin }}$ & 0.1 & $d^{-1}$ & $(\star)$ \\
\hline Sinking velocity for small detritus & $w_{S D}$ & 0.1 & $m d^{-1}$ & $(\star)$ \\
\hline Sinking velocity for large detritus & $w_{L D}$ & 10.0 & $m d^{-1}$ & $(2,5)$ \\
\hline Sinking velocity for phytoplankton & $w_{\text {Phyto }}$ & 0.1 & $m d^{-1}$ & $(\star)$ \\
\hline Sinking velocity for chlorophyll a & $w_{C h l a}$ & 0.1 & $m d^{-1}$ & $(\star)$ \\
\hline Oxidation of $\mathrm{NH}_{4}$ to $\mathrm{NO}_{3}$ (nitrification) & $t_{\text {nitri }}$ & 0.1 & $d^{-1}$ & $(\star)$ \\
\hline
\end{tabular}

Figure 3 shows the net heat flux obtained from OAflux data base. Maximal values (around $150 \mathrm{~W} / \mathrm{m}^{2}$ ) occur in July-August and minimal negative values occur from November to February, leading to winter convection, the main factor producing mixed layer deepening.

Figure 4 illustrates the annual cycle of wind stress from NCEP reanalysis. Maximum intensities about $0.1 \mathrm{~N} / \mathrm{m}^{2}$ were reached during summer months due to an increase in the strength of the Trade Winds. As explained in Sec. 5 the stabilizing effect of a maximum positive net heat flux in summer and the destabilizing effect of wind stress during this period leads to the maximal stratification in autumn.

Freshwater flux annual cycle (ECMWF reanalysis) is shown in Fig. 5. Values range from $0.065 \mathrm{~cm} /$ day in summer to $0.1 \mathrm{~cm} /$ day in winter and are weak in comparison with temperate regions.

Sea surface temperature (SST, Fig. 5) is required to correct the heat fluxes because of the sensitivity of the surface net heat flux to the SST (Haney, 1971; Killworth et al., 2000). The maximum is reached in September, after the Trade Winds weaken.

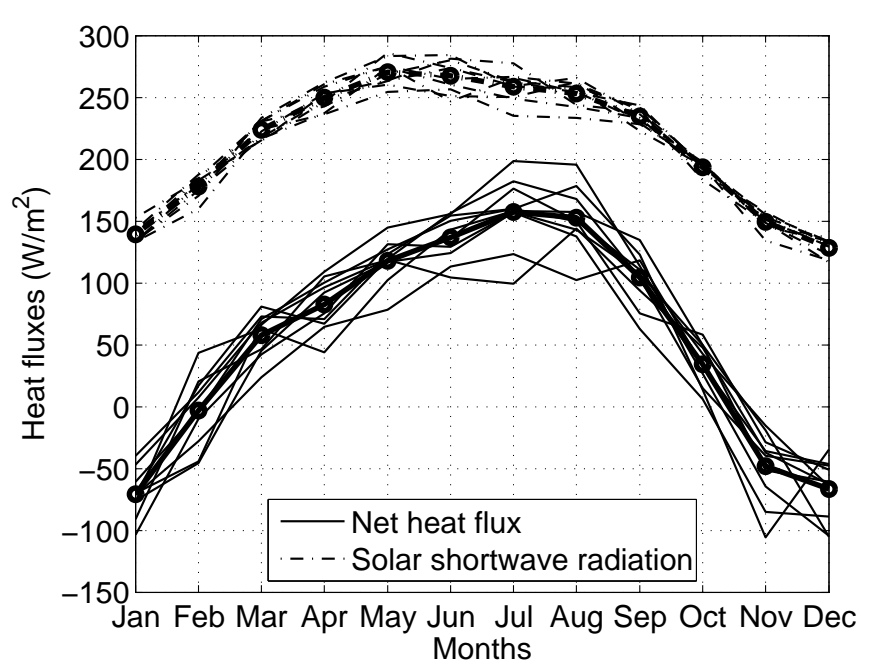

Fig. 3. Mean cycles (bold line) and individual years from 1993 to 2002 (thin lines) of surface net heat flux (plain lines) and solar shortwave radiation (dashed lines) from OAflux.

\subsection{Initialization}

The model was initialized in Mid-August with in situ profiles of temperature, salinity, nitrate and oxygen con- 


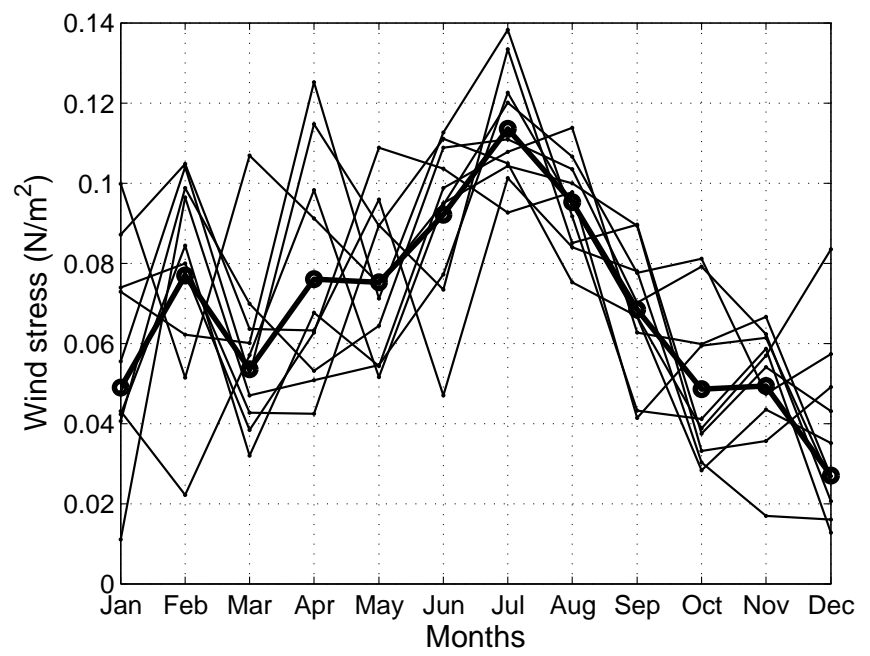

Fig. 4. Same as Fig. 3, but for wind stress from NCEP Reanalysis.

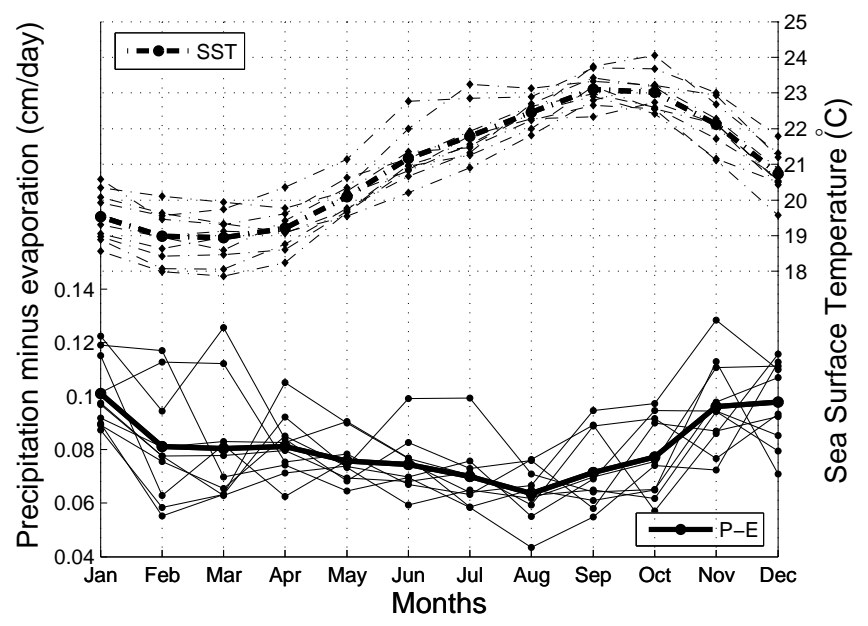

Fig. 5. Sea Surface Temperature from NOAA OI SST V2 and freshwater flux from ECMWF 40 Years Re-Analysis.

Table 2

Sources of reanalyzed data used for model forcing.

\begin{tabular}{ll}
\hline Data & source \\
\hline SST & $\begin{array}{l}\text { NOAA optimum interpolation SST V2 (Reynolds } \\
\text { et al., 2002) }\end{array}$ \\
NHFLux & $\begin{array}{l}\text { Objectively Analyzed Air-Sea Fluxes (OAFlux) for } \\
\text { the Global Oceans (Yu et al., 2004; Yu and Weller, }\end{array}$ \\
& $\begin{array}{l}\text { 2007; Zhang et al., 2004) } \\
\text { FWFlux }\end{array}$ \\
ECMWF 40 Years Re-Analysis (Uppala et al., 2005) \\
WStress & $\begin{array}{l}\text { CDC Derived NCEP Reanalysis Products Surface } \\
\text { Flux (Kanamitsu et al., 2002) }\end{array}$ \\
\hline
\end{tabular}

centrations from the FAX cruise (Barton et al., 2004). Vertical profiles were averaged within the region of interest and fitted with fourth-order polynomials, in order to have analytical expressions for input to the model. Higher order polynomials were tested but resulted in large oscillations that were not physically realistic. With this averaging, the spatial variability inherent to the zone surveyed during the FAX campaign is removed.
Salinity profiles (Fig. 6) show the decrease of salinity with respect to depth below the mixed layer. This negative salinity gradient is characteristic of subtropical regions, where evaporation and solar radiation are high throughout the year (Figs. 3 and 5). This situation is favorable to double diffusion through salt-fingering and therefore enhances mixing (Pérez et al., 2001).

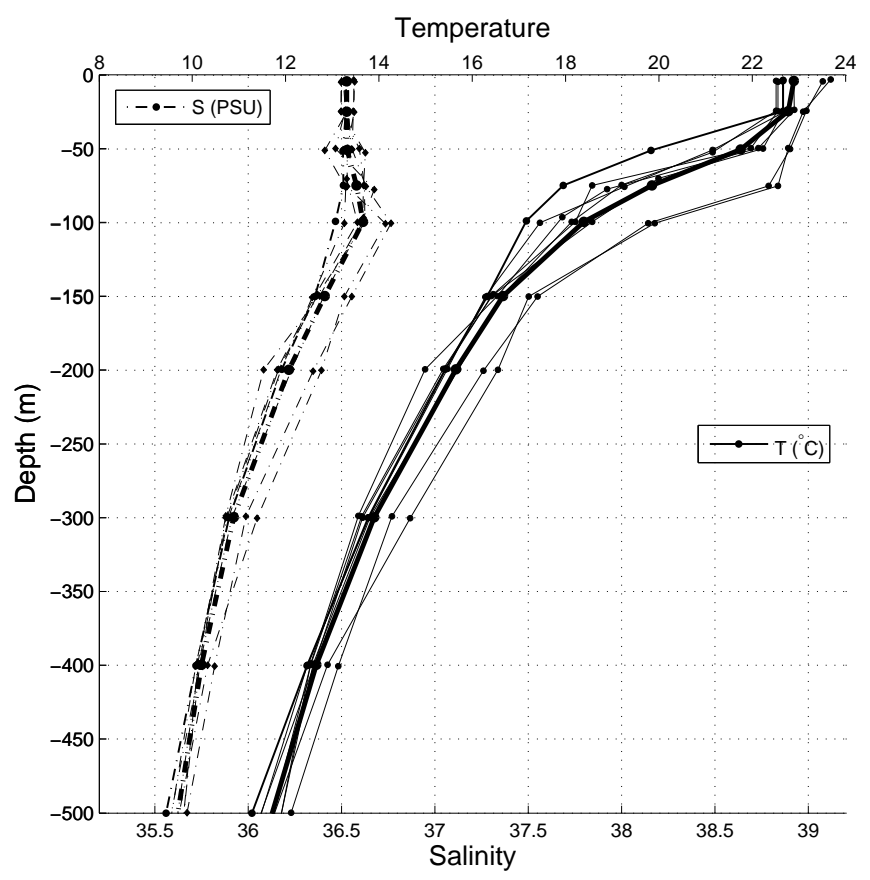

Fig. 6. Profiles of temperature and salinity used for model initialization. Bold lines represent mean values obtained from individual FAX profiles (thin lines).

Oxygen surface concentration is slightly lower than 5 $\mu \mathrm{mol} / \mathrm{m}^{3}$ and reaches its maximum around $75 \mathrm{~m}$. Nitrate has very low concentrations $\left(\leq 1 \mu \mathrm{mol} / \mathrm{m}^{3}\right)$ in the first 100 $\mathrm{m}$, then quickly increases to reach more than $15 \mu \mathrm{mol} / \mathrm{m}^{3}$ at $500 \mathrm{~m}$.

The other physical and biological variables are assigned with constant values over the water column:

- The initial velocities were set to zero.

- The initial value for the vertical mixing coefficient for momentum $\left(K_{M}\right)$ was $0.01 \mathrm{~m}^{2} / \mathrm{s}$.

- The vertical mixing coefficients for salinity $\left(K_{S}\right)$ and temperature $\left(K_{T}\right)$ were taken equal to $0.001 \mathrm{~m}^{2} / \mathrm{s}$.

- The remaining biological variables were initialized with constant values representative of the region (Tab. 3). In the case of zooplankton, measured values were converted into units compatible with the model $\left(\mathrm{mMol} \mathrm{N}_{2} \mathrm{~m}^{-3}\right)$ using conversions factors of zooplankton biomass from Harris et al. (2000). For ammonium, the mean value obtained from numerical simulations (Bahamón and Cruzado, 2003) is assigned as the initial condition. 
Table 3

Initial values for the biological variables. $(\star)$ denotes default values. Phytoplankton was initialized using the maximal chlorophyll/phytoplankton ratio.

\begin{tabular}{llll}
\hline Variable & Unit & Prescribed value & Source \\
\hline Ammonium & $m \mathrm{~mol} \mathrm{~N}_{2} m^{-3}$ & 0.1 & Bahamón and Cruzado (2003) \\
Chlorophyll a & $m g \mathrm{Chl}_{a} m^{-3}$ & 0.5 & Arístegui et al. (1997) \\
Phytoplankton & $m \mathrm{Mol} \mathrm{N}_{2} m^{-3}$ & 0.1187 & Redfield (1934) \\
Zooplankton & $m \mathrm{Mol} \mathrm{N}_{2} m^{-3}$ & 0.06 & Hernández-León et al. (2007) \\
Small detritus & $m \mathrm{~mol} \mathrm{~N}_{2} m^{-3}$ & 0.04 & $(\star)$ \\
Large detritus & $m \mathrm{~mol} \mathrm{~N}_{2} m^{-3}$ & 0.02 & $(\star)$
\end{tabular}

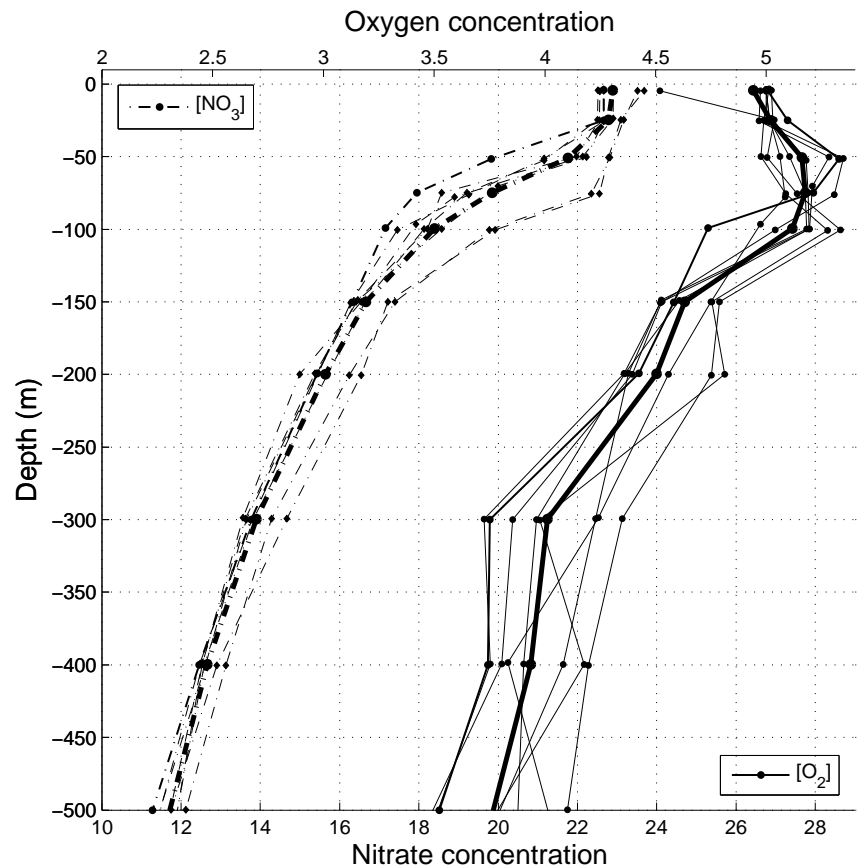

Fig. 7. Same as Fig. 6 but for oxygen and nitrates.

\subsection{Model setup}

The simulation parameter values were chosen to produce an annual cycle and to satisfy the numerical constraints of stability. Numerous runs were made to determinate suitable values.

The model was run for 6 years to steady state conditions, with a time step $\Delta t=60 \mathrm{~s}$. Results were stored once a day, which removes short time scale variability.

The water column was limited to the first $500 \mathrm{~m}$ and discretized on a staggered grid. The depth of the $i^{\text {th }}$ layer is given by

$$
d(i)=-h \frac{\sinh \left(\theta \frac{N-i}{N}\right)}{\sinh (\theta)}, \quad i=\{0,1, \ldots, N\},
$$

with $h$ the total depth, $N$ the number of layers and $\theta$, a parameter for the adjustment of the grid spacing. The number of layers $N$ was chosen to be 40 . A larger number of layers increased the computational time without giving significant differences in the results. $\theta$ was taken equal to 4 to have a fine resolution $(\approx 1.5 \mathrm{~m})$ near surface.

\section{Model testing}

Before performing simulations with the forcing and initial conditions described in sections 3.1 and 3.2, respectively, the KPP model is compared with other mixed layer models using idealized experiments. These experiments were not designed to be representative of the conditions of the region of interest, but to provide common configurations for evaluating the mixing submodels.

\subsection{Description of the experiments}

In each experiment, latitude was taken to be $29.91^{\circ} \mathrm{N}$, which gives an inertial period close to 24 hours, and allows comparisons with similar results from other models. The vertical resolution is uniform over the water column with $\Delta z=2 \mathrm{~m}$. The velocity is initialized with zero value in each direction. The experiments are described hereinafter.

(i) the deepening experiment (Exp.I) was designed to examine the effects of wind stress on the water column stability. It consists of a wind with constant direction and intensity $\left(\tau=0.4 \mathrm{~N} / \mathrm{m}^{2}\right)$ for 5 days. The initial temperature was set to $24^{\circ} \mathrm{C}$ at surface, with a thermal stratification of $0.05^{\circ} \mathrm{C} / \mathrm{m}$. The surface net heat flux was set to zero.

(ii) the cooling experiment (Exp.II) showed mixed layer deepening due to convective mixing produced by a negative heat flux. Initial conditions were the same as the previous experiment; wind stress was assigned a constant value $\tau=0.1 \mathrm{~N} / \mathrm{m}^{2}$ and surface net heat flux was taken to be $-96.8 \mathrm{~W} / \mathrm{m}^{2}$. The experiment was run for 120 days.

(iii) the heating experiment (Exp.III) illustrated mixed layer shallowing when the ocean experiences a positive net heat flux. The initial conditions were the same as the two previous cases, except that temperature was initialized with a constant value of $T=$ 
$19{ }^{\circ} \mathrm{C}$. The wind stress was equal to $\tau=0.1 \mathrm{~N} / \mathrm{m}^{2}$ and the net heat flux was $290.4 \mathrm{~W} / \mathrm{m}^{2}$.

\subsection{Description of the models}

The KPP model is compared with five other models: the Mellor-Yamada level 2 (MYL 2) and level 2.5 (MYL 2.5) closures (Mellor and Yamada, 1974), the Niiler (Niiler and Kraus, 1977, Nii.), Garwood (Garwood, 1977, Gar.) and Price-Weller-Pinkel (Price et al., 1986, PWP) models. The first two models belong to the category of differential models, i.e. governing equations in their primitive form are used, while the three other models belong to the category of integrated models, i.e. governing equations are integrated over the mixed layer depth. Results of the experiments are summarized in Tab. 4. For each experiment the MLD computed with ROMS 1D is compatible with the values obtained with the other models.

Table 4

Mixed layer depth (in meters) in different experiments with 6 models.

\begin{tabular}{lllllll}
\hline Models & MYL2 & MYL2.5 Nii. & Gar. & PWP & ROMS 1D \\
\hline Exp.I & 39 & 39 & 54 & 51 & 54 & $\mathbf{4 2}$ \\
Exp.II & 101 & 103 & 127 & 117 & 101 & $\mathbf{1 1 0}$ \\
Exp.III & 14 & 14 & 4 & 14 & 8 & $\mathbf{7}$ \\
\hline
\end{tabular}

\section{Numerical results}

\subsection{Physics}

Annual fields generated with the forcing described in section 3.1 and with the parameters of section 3.3 are presented.

\subsubsection{Temperature}

Temperature (Fig. 8) reached a maximum from late $\mathrm{Au}-$ gust to mid-October with values around $23^{\circ} \mathrm{C}$. The temperature maximum does not occur when the heat flux was maximum (July-August), but rather in September, after the period of peak insulation. This arises because of the destabilizing effect of Trade Winds, which reach their maximal intensity in July-August (Fig. 4). Along with this maximal temperature, a strong stratification takes place under the influence of intense solar heating.

From February to May, strong convective mixing took place and generated minimum temperatures around $18^{\circ} \mathrm{C}$. The variability induced by air-sea fluxes affected only the upper $125 \mathrm{~m}$ of the water column, since temperature is fairly constant below this depth.

\subsubsection{Mixed layer depth}

The MLD is the upper part of the water column where properties are distributed quasi homogeneously. This physical property does not only accounts for the influence of
( C)

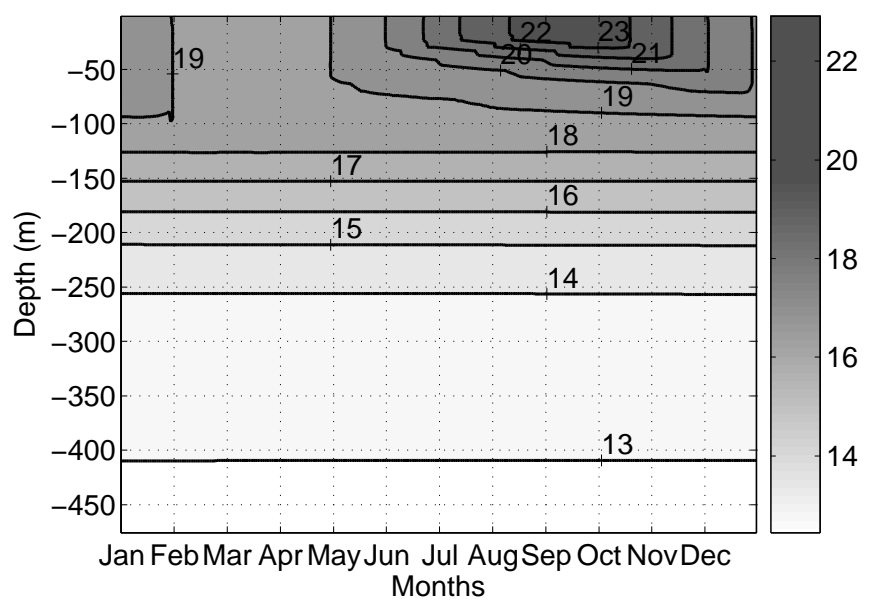

Fig. 8. Annual temperature field obtained with ROMS 1D.

each forcing parameter (wind, surface temperature, precipitation, heat fluxes), but also strongly determines biochemical cycles.

The annual evolution of mixed layer computed with ROMS 1D model (Fig. 9, plain line) follows the temperature behavior: the mixed layer is deepest in February $(>100 \mathrm{~m})$ after a period of convective mixing starting in November. Then shallowing starts as net heat flux increases and reaches a value around $25 \mathrm{~m}$ between July and September, despite intense summer Trade Winds (Fig. 4). Deepening starts again after September, under the effect of decreasing surface net heat flux.

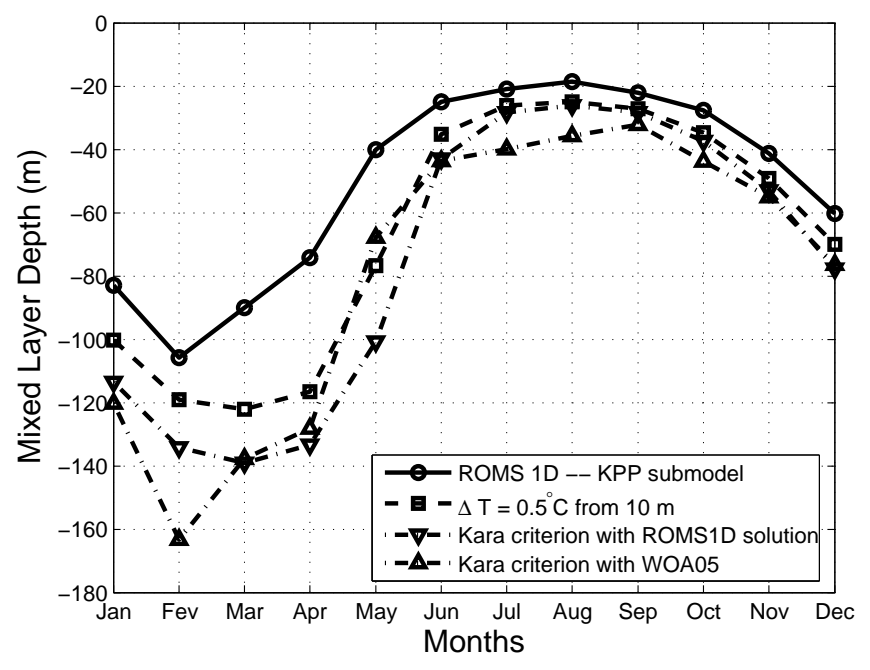

Fig. 9. Mixed layer depth: ROMS 1D - KPP model (plain line), same temperature criterion as Neuer et al. (2007) (dashed line with $\square)$, density criterion from Kara et al. (2000) applied to ROMS 1D solution (dashed line with $\nabla$ ) and to WOD05 climatology (dashed line with $\triangle$ ). 


\subsection{Biology}

\subsubsection{Phytoplankton}

As illustrated in Fig. 10, maximal phytoplankton concentrations appear in February in the first $100 \mathrm{~m}$. This maximum is explained by a nutrient injection into the euphotic zone provoked by the thermocline erosion induced by winter convective mixing. From mid-June, a deep maximum, also visible in the chlorophyll field (Fig. 11), develops.

Beyond $150 \mathrm{~m}$, phytoplankton concentrations are very small $\left(\mathcal{O}\left(10^{-4}\right)\right.$ mMol $\left.N_{2} m^{-3}\right)$. From a simple point of view, phytoplankton needs two ingredients to grow: light and nutrients. Since light decreases exponentially with depth, it becomes insufficient to sustain phytoplankton growth, even though a sufficient amount of nutrients is available.

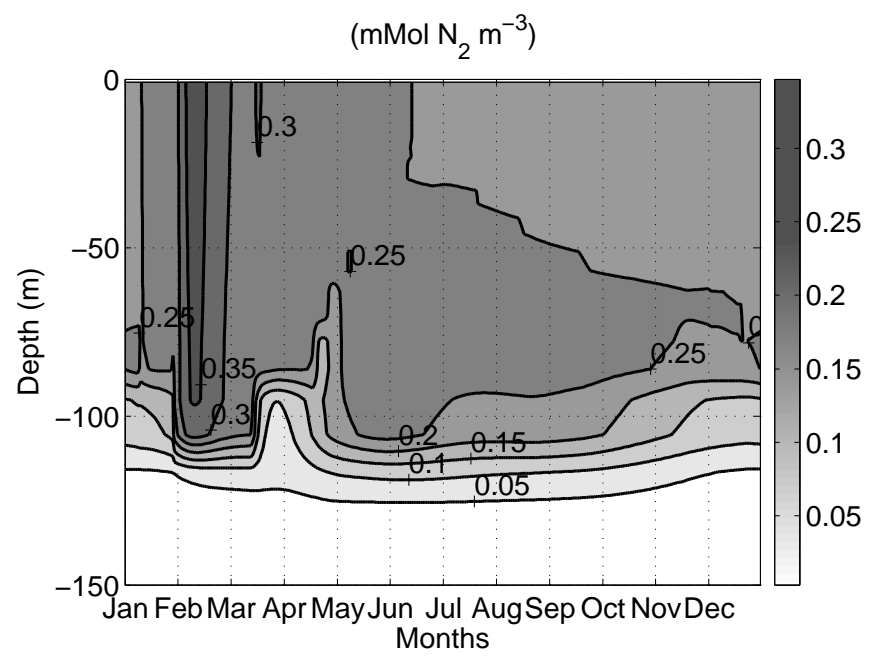

Fig. 10. Phytoplankton concentration obtained with ROMS 1D.

\subsubsection{Chlorophyll}

Among the numerous variables of the model, it is particularly interesting to present chlorophyll concentrations, since this variable was initialized with a constant value, allowing the model to show its capability to reproduce real profiles by itself.

Figure 11 shows a homogeneous mixed layer of low chlorophyll above a deep chlorophyll maximum (DCM) developed in spring and summer, with maximal concentrations around $1 \mathrm{mg} C h l_{a} \mathrm{~m}^{-3}$ at $100 \mathrm{~m}$. Surface concentrations range from $0.4 \mathrm{mg} C h l_{a} \mathrm{~m}^{-3}$, when the mixed layer is deepest, to $1 \mathrm{mg} C h l_{a} m^{-3}$ in summer.

\subsubsection{Summary}

In order to summarize the annual biological cycle, concentrations between surface and a reference depth (the euphotic depth) are integrated. The light-depth relationship used in the model gives an estimated euphotic depth of 72.8 $\mathrm{m}$.

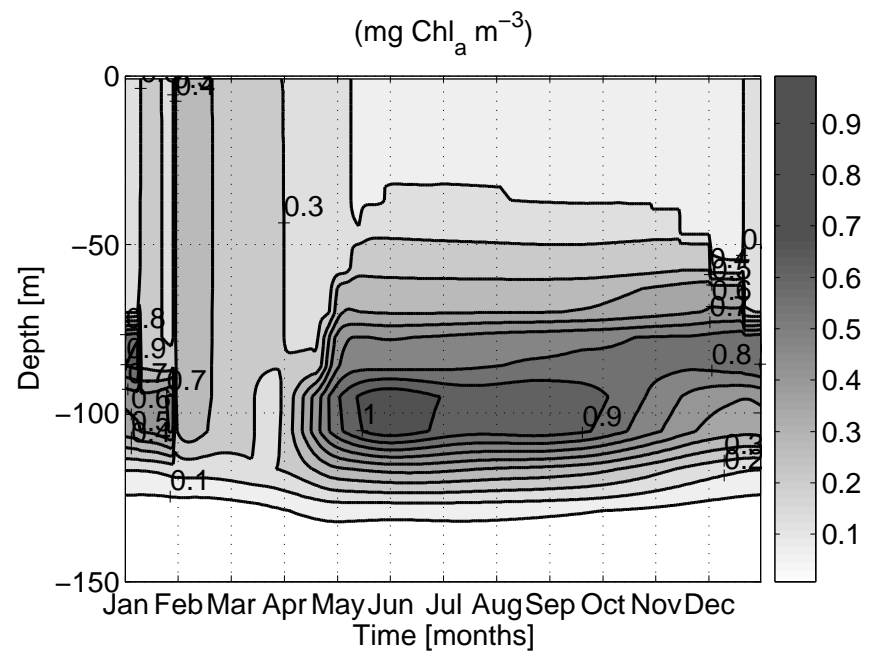

Fig. 11. Chlorophyll concentration between surface and $150 \mathrm{~m}$ as obtained from ROMS 1D.

Zielinski et al. (2002) compared four water light-field models and found a range for the $1 \%$ depth between 81 and $139 \mathrm{~m}$ in winter, and between 83 and $133 \mathrm{~m}$ in spring. The choice of the range for the integration modifies quantitatively the results, but the studied mechanisms are still the same.

The late-winter bloom is made up of three stages:

(i) A peak in nutrients in early February, due to convective mixing.

(ii) High phytoplankton concentrations in mid-February around $25 \mathrm{mMol} \mathrm{N}_{2} \mathrm{~m}^{-3}$.

(iii) A zooplankton bloom beginning by the end of March. According to the biological model, zooplankton concentration is enhanced by grazing of phytoplankton and is diminished by metabolism, death and excretion. It is then assumed that the origin of the time lag and the longer duration of zooplankton bloom comes from the quantity of phytoplankton made available during the short bloom period.

After these three stages, concentrations decrease as nutrients becomes less available while the thermocline starts to reform. The evolution of detritus concentration is similar to that for the zooplankton, with a maximum between March and May and a quasi steady decrease until the end of December. This similarity arises because the main processes that drive detritus evolution are mortalities of phytoplankton and zooplankton along with the part of zooplankton that is not assimilated.

\section{Validation}

Results are compared with the following sources:

- climatological fields extracted from the World Ocean Atlas 2005 (Locarnini et al., 2006, WOA05 herinafter) and averaged over the area of interest. Using climatological values is compatible with the general goal of simulating annual cycles. The WOA05 offers monthly climatology 


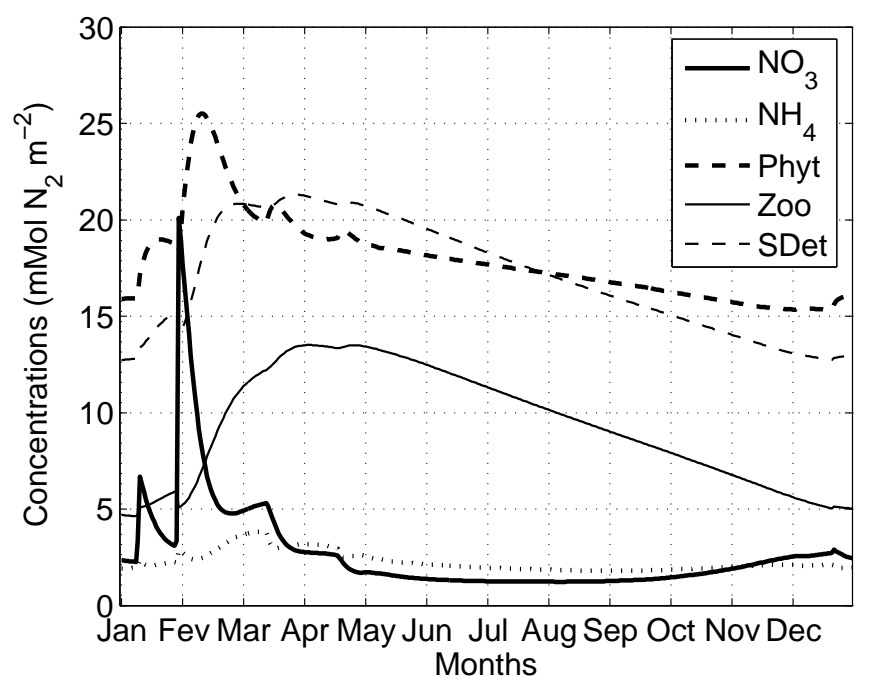

Fig. 12. Concentrations integrated from euphotic depth to surface as obtained from ROMS 1D.

for temperature, salinity from 0 to $1500 \mathrm{~m}$ on 24 levels, and for oxygen and nitrates from 0 to $500 \mathrm{~m}$ on 14 levels;

- in situ data extracted from the World Ocean Database and from campaigns carried around Gran Canaria.

- measurements from ESTOC station, keeping in mind that the conditions are not exactly the same.

\subsection{Temperature field}

Figures 8 and 13 show the same near-surface structure: intense mixing and low temperatures during winter, formation of thermocline in spring, strong stratification and maximal temperatures in summer.

Differences between the model results and WOA05 climatology are attributed to the use of a one-dimensional model, which prevents the existence of vertical velocity and advection. The Canary Islands are influenced by the cool Canary Current, which is not included in the model forcing, which results in the modeled temperature maximum being higher than values from the WOA05.

The numerical results are also in agreement with measurements at ESTOC station: Neuer et al. (2007):

- a surface temperature of $18^{\circ} \mathrm{C}$ along with a deep mixing from January to March,

- a stratification starting in June and a mixed layer depth around $40-50 \mathrm{~m}$,

- a maximal temperature during September around $24^{\circ} \mathrm{C}$.

\subsection{Mixed layer depth}

There are several ways to compute the MLD, as illustrated on Fig. 9. A complete review is found in de Boyer Montgut et al. (2004). The MLD computed by ROMS 1D is based on KPP model. In this formulation (Large et al., 1994, Eq. (21)), the MLD is the smallest depth value that makes the bulk Richardson number equal to its critical

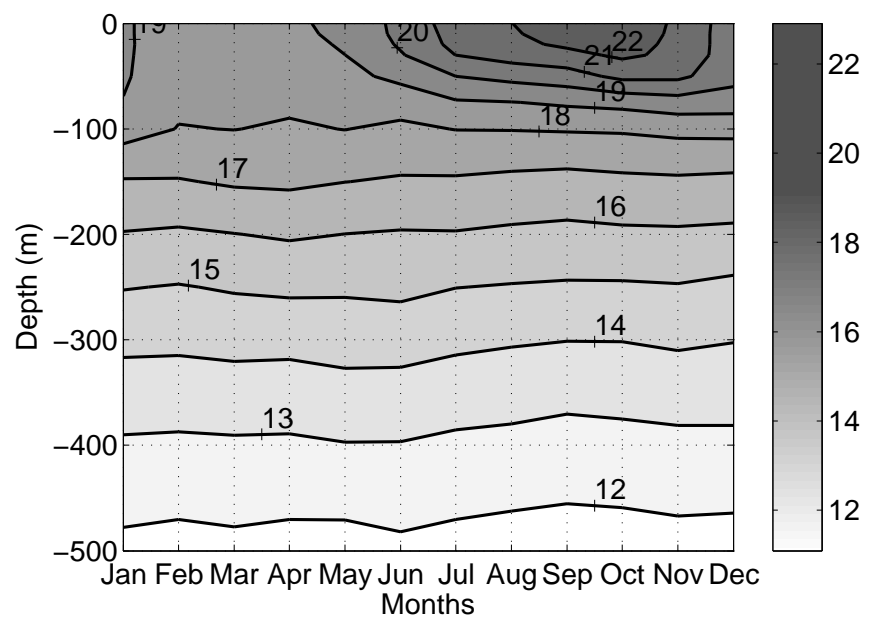

Fig. 13. Annual temperature field from WOA05 Monthly Long Term Mean temperature.

value $\mathrm{Ri}_{c r}$. Hence using this definition, both stratification and shearing are considered.

The main characteristics of the MLD annual cycle calculated from the model (plain curve with circles) are correctly reproduced: a winter deepening caused by convective mixing and a summer shallowing induced by strong heat flux.

In Neuer et al. (2007), a winter MLD varying from 100 $\mathrm{m}$ in 1997 to $200 \mathrm{~m}$ in 1994 is shown. For comparisons with ESTOC station, the model MLD was computed following the same criterion (temperature difference of $0.5^{\circ} \mathrm{C}$ with respect to the value at $10 \mathrm{~m}$ ). Doing so, the mixed layer is deepest (around $120 \mathrm{~m}$ ) from February to March (Fig. 9).

A more sophisticated method from Kara et al. (2000) is based on a density difference criterion from a reference depth, hence it permits the consideration of variable salinity. This method was applied on both ROMS 1D results and WOA05 climatology of temperature and salinity, yielding a unique criterion for comparison.

Results are very similar from June to December, with a maximal difference being close to $20 \mathrm{~m}$. In winter and spring, differences larger than $50 \mathrm{~m}$ are encountered. Possible explanations are the lack of resolution of the model at these depths and the mathematical definition of MLD.

Nevertheless, the four curves represent the same physical processes, regardless of the selected MLD formulation.

\subsection{Nitrates}

In Fig. 14 climatological (WOA05, Garcia et al., 2006b) and in situ (Braun, 1976) data are compared with the annual cycles of nitrates obtained with the model. In each plot, orders of magnitude are close, suggesting that the coupled ecosystem model produced coherent results.

However two main differences appear: 1 . the shape of the iso- $\mathrm{NO}_{3}$ : in the numerical results, they are close to horizontal, while in the climatology and in situ data, vertical displacements occur. Once again, the absence of vertical velocity in the $1 \mathrm{D}$ model may justify these observations; 2 . 
vertical gradient of $\mathrm{NO}_{3}$ is larger in the simulations than in the climatology. This may be a consequence of the stretched grid (lower resolution as the depth increases) or of the intrinsic efficiency of the model.

Near surface concentrations are very low (maximum of $0.45 \mathrm{mMol} N^{2} \mathrm{~m}^{-3}$ in the first $75 \mathrm{~m}$ ), in agreement with Neuer et al. (2007), who reported undetectably small measurable values $\left(<1 \mathrm{mMol} N^{2} \mathrm{~m}^{-3}\right)$ in the mixed layer.

\subsection{Phytoplankton and zooplankton}

Validation of plankton variables is not as direct as for nutrients or oxygen, since no climatologies exist for these. Moreover, all the phytoplankton and zooplankton species are represented by two aggregated state variables([phyto] and $[z o o])$ in the model, whereas several groups are usually considered (e.g. pico-, nano- phytoplankton, mesozooplankton, ...). For these reasons, their evolution will be discussed qualitatively.

\subsubsection{Phytoplankton}

Arístegui et al. (2001) measured the biomass between March 1988 and June 1989, with the closest sampling (one week) during winter bloom: maxima of integrated concentration occur in late winter and are composed of two peaks (see their Fig. 3a), one in mid-February and the other in mid-March. These observations are coherent with the numerical results (Figs. 10 and 15), where two distinct period of high phytoplankton concentration in the first $20-25 \mathrm{~m}$ are present.

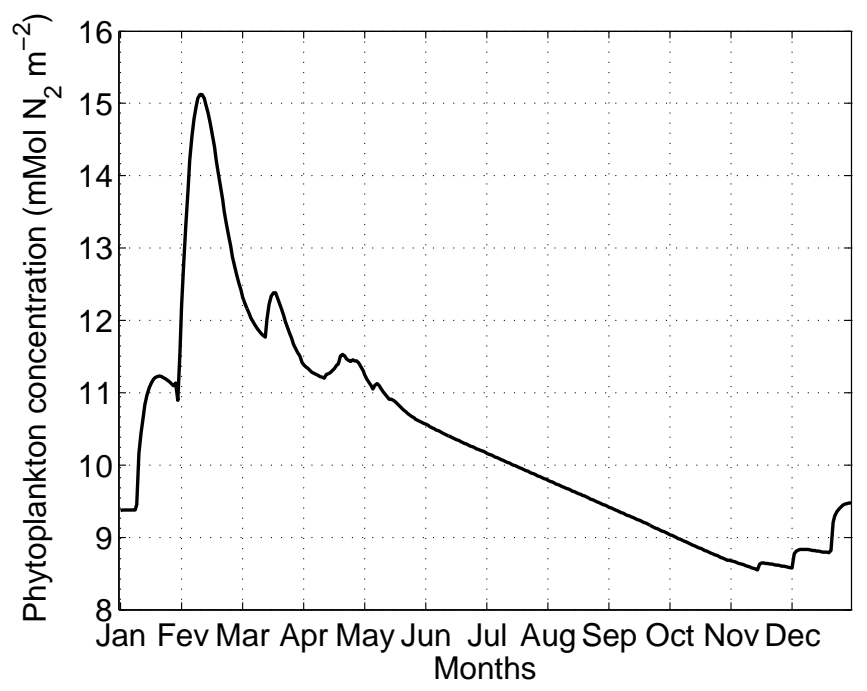

Fig. 15. Integrated phytoplankton concentration obtained with the model in the 40 first $\mathrm{m}$.

\subsubsection{Zooplankton}

In Fig. 12 the zooplankton bloom takes place with a time lag with respect to the phytoplankton bloom, in agreement with observations from Hernández-León et al. (1984) and Arístegui et al. (2001). However, with this exception, the biological model was not able to reproduce the typical features of the zooplankton cycle.

Hernández-León et al. (2004) measured the average and zooplankton biomasses (their Figs. 3 and 6) and showed a clear maximum by the end of February, while ROMS 1D results show a maximum extending over several days in late March. They also reported a maximum in July, mentioned in Braun (1976), and attributed it to intense Trade Winds during these months. This feature was not reproduced by the model.

As stated previously, differences between model and reality originate from the use of a single variable to represent zooplankton. The Canary Island waters are characterized by a production mainly driven by mesozooplankton. Advection of biological properties, through upwelling filaments for example, may also contribute to such discrepancies.

\subsection{Chlorophyll a}

Figure 11 shows results that are in agreement with measurements of Neuer et al. (2007), who showed concentrations higher than $0.5 \mathrm{mg} C h l_{a} \mathrm{~m}^{-3}$ near the euphotic depth and Barton et al. (2000) who reported values higher than $0.6 \mathrm{mg} C h l_{a} \mathrm{~m}^{-3}$ in the lee region of Gran Canaria. According to Tett et al. (2002), this DCM results from a steadystate balance between the limitation of phytoplankton production due to light and losses due to exported production and local metabolism of microplankton.

Simulated surface concentrations agree with the observations of Neuer et al. (2007): highest values (up to $0.4 \mathrm{mg}$ $C h l_{a} m^{-3}$ ) when the mixed layer is deepest and lower values around $0.05 \mathrm{mg} C h l_{a} \mathrm{~m}^{-3}$ (1 $\mathrm{mg} C h l_{a} \mathrm{~m}^{-3}$ in simulations) in summer. Arístegui et al. (2001) reported a small chlorophyll bloom, with values larger than the annual mean, but lower than those encountered in temperate regions.

Comparison with in situ data from the FAX cruise (Barton et al., 1998) is made in Fig. 16. Variations from one day to another cannot be captured by one-dimensional model, as they may come from the complex circulation pattern of the region. However, the model shows distributions that agree in structure and magnitude.

Comparisons with Zielinski et al. (2002) show good agreement. The simulated and observed DCM appears at similar depths. Moreover, ROMS 1D results compare quantitatively better to the ESTOC observed values than do the simulated results presented in Zielinski et al. (2002) (see their Fig. 10).

\subsection{Oxygen}

The simulated oxygen annual cycle (Fig. 17(a)) is compared with climatological fields (Garcia et al. (2006a), Fig. 17(b)). Both show similar orders of magnitude and a high near-surface concentrations above $5 \mathrm{mMol} \mathrm{O}_{2} \mathrm{~m}^{-3}$ at the end of winter. Another surface structure with oxygen concentrations around $5 \mathrm{mMol} \mathrm{O}_{2} \mathrm{~m}^{-3}$ occurs in the summer. 


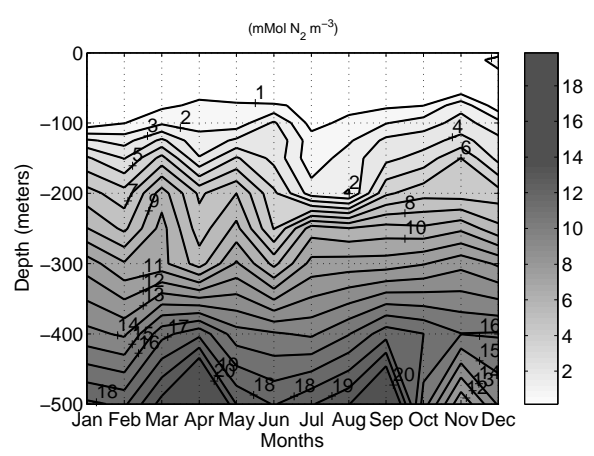

(a) WOA 2005

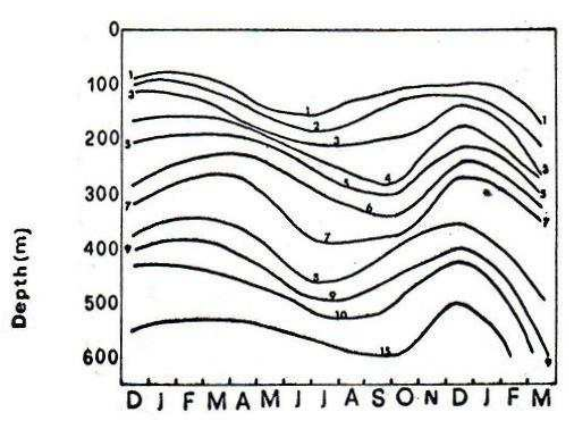

(b) In situ

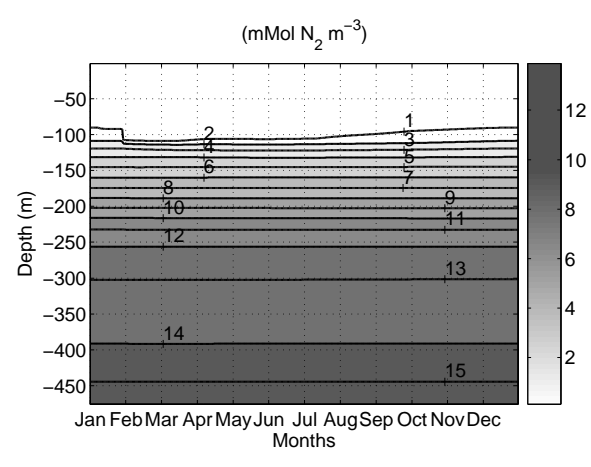

(c) ROMS 1D

Fig. 14. Annual field of nitrate concentration: (a) World Ocean Atlas 2005, (b) measurements 5 miles east off Tenerife (reproduced from Braun (1976)), (c) model results.

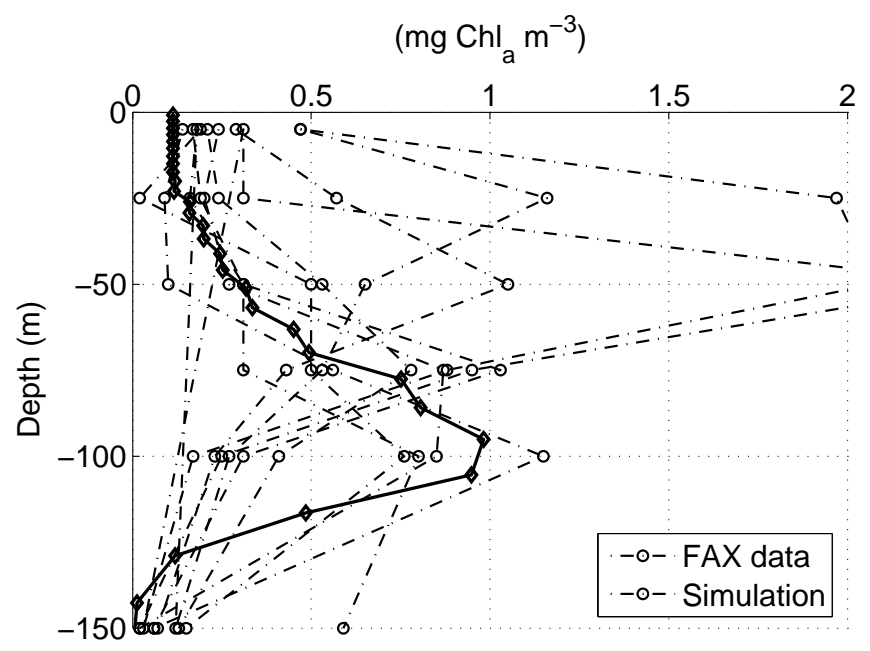

Fig. 16. Model results (bold lines) and in situ measurements (Barton et al., 1998) for the chlorophyll concentration between 7th and 9th of August.

The differences seen between the simulated and observed nitrate values model are also visible in the oxygen distributions.

\section{Discussion}

More than 50 years ago, Sverdrup (1953) developed a model to explain the spring bloom of phytoplankton and the conditions underlying its formation. His theory states that the phytoplankton growth season starts in early spring, when the mixed layer depth becomes shallower than the critical depth. Critical depth depth is defined as the depth above which the depth-integrated daily gross primary production equals respiration, i.e. the depth above which integrated net daily primary production equals zero (Nybakken, 2001).

The assumptions underlying this theory are:

(i) phytoplankton cells are uniformly distributed in the mixed layer,

(ii) photosynthesis is assumed to decrease exponentially with depth, as the light does,

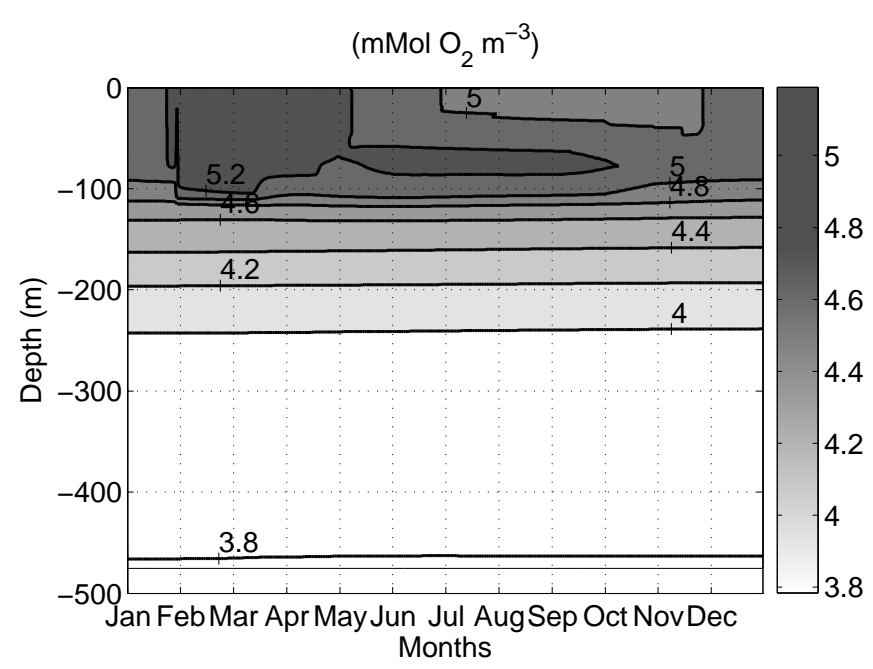

(a) ROMS 1D

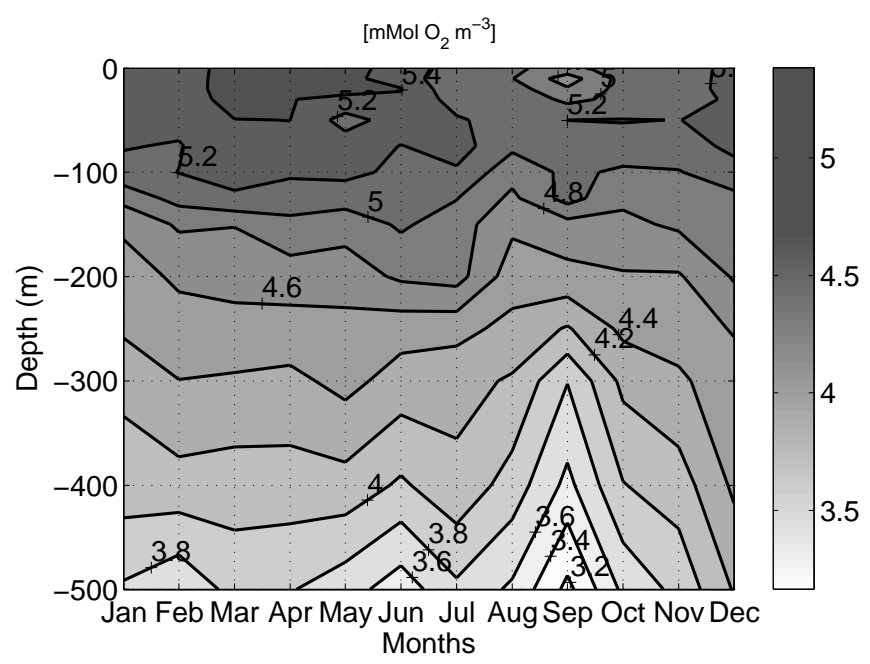

(b) WOA 2005

Fig. 17. Annual field of oxygen concentration: (a) Results from simulation, (b) WOA05. 
(iii) respiration is considered to be constant over the mixed layer.

The critical depth was calculated using the average value of light $\bar{I}_{D}$ penetrating into the euphotic zone. This average amount of light is obtained by integrating the relation between depth and light intensity

$$
I_{\lambda}(z)=I_{\lambda, 0} \exp \left(-k_{\lambda} z\right)
$$

from the surface $(z=0)$ to the depth $D$, which leads to

$$
\bar{I}_{D}=\frac{\bar{I}_{0}}{k D}\left(1-e^{-k D}\right) .
$$

The previous equation is used to get an expression for the critical depth $D_{c r}$. Assuming that phytoplankton cells move up and down in the mixed layer, they receive on average a light intensity equal to $\bar{I}_{D}$. The critical depth is then the depth at which $\bar{I}_{D}$ equals to $I_{C}$, the compensation light intensity, defined as the amount of light that makes production and loss equal. The compensation depth is the depth at which that equality is satisfied.

Combining the previous definition with Eq. (3), the compensation depth is calculated by

$$
D_{c}=\frac{\ln \left(I_{0}\right)-\ln \left(I_{C}\right)}{k},
$$

Finally, the substitution of $\bar{I}_{D}$ by the compensation light intensity $I_{C}$ in (4) yields

$$
D_{c r .}=\frac{\bar{I}_{0}}{k I_{C}}\left[1-\exp \left(-k D_{c r .}\right)\right]
$$

The compensation depth depends on the clarity of water and thus varies over the world oceans. However, according to Nybakken (2001), the euphotic depth is a good estimate. Solving Eq. (6) with this approximation, a critical depth equal to $113 \mathrm{~m}$ was found. As the MLD depends on the way it is defined (see Fig. 9), interpretation of Sverdrup's critical depth theory is not straightforward.

The MLD computed from the ROMS 1D simulation results results in a critical depth that is deeper than the MLD all year long, which is typical for subtropical regions (Arístegui et al., 2001). However, if other methods are used to compute the MLD, there is an intersection between critical and mixed layer depths, taking place during April, which disagrees with the observation of a late-winter phytoplankton bloom.

Hence it is concluded that the mixed layer depth is a control on the timing of the biological cycles, even if Sverdrup's theory could not be applied in the region of interest.

\section{Conclusions}

\subsection{Physics}

Physical processes south of Gran Canaria were successfully simulated using the ROMD 1D model. Maximal surface temperatures and strongest stratification were produced in late summer-early fall, when the Trade Winds have started to weaken. The deepest mixed layer of about $100 \mathrm{~m}$ occurs in February, under the effect of negative heat flux, in agreement with observations and with existing climatologies. The correct representation of this physical feature is a first step in development of a model to understand the biogeochemical processes.

The differences between numerical results and data (in situ or climatological) are believed to be due to the following:

- The nature of a 1-D model: neither advection nor vertical velocity exists.

- Forcing is carried out with monthly values linearly interpolated at each time step, thus processes with shorter time scale are filtered out.

However, even with these differences mean seasonal cycles were simulated.

\subsection{Biology}

A strong coupling between air-sea fluxes and biological cycles was observed:

- the phytoplankton bloom occurs in late winter, when surface temperature is minimum because of convective mixing produced by negative heat flux.

- From early spring to late fall, biological concentrations tend to decrease under the effect of the shallow seasonal thermocline formed by intense heating.

This cycle contrasts with what is usually observed in temperate regions, where a phytoplankton bloom occurs in early spring, strongest mixing in winter, due to maximal wind velocities during this season, and maximal temperatures in summer.

Primary production in the Canary Island region is nutrient-limited, as there is a sufficient amount of light received by the water column all year long, while in temperate regions, primary production is light limited, as the mixing is strong enough to feed the euphotic layer with new nutrients during most of the year.

Numerous biological models have been described in the literature and some were primarily designed to work within a pre-determinate domain of the sea. As a model is always an idealization of reality, it has to be accepted that some processes may not be accurately modeled or well parametrized. Nevertheless, the ecosystem model coupled with the physical model yielded results that correspond to observed patterns for most of the simulated variables.

\subsection{Perspectives}

Further work should concentrate on the computation of the critical depth with a more detailed model, to test the applicability of Sverdup's theory to the Canary Island waters. Some of the parameters in the biological model require modifications that should be based on measurements and/or experiments carried out in the Canary Island region. Additional improvement to the ecosystem model sim- 
ulations would be gained by separating the zooplankton component into several compartments.

\section{Acknowledgments}

The authors are very grateful to two anonymous reviewers for their constructive comments which contributes to deeply improve the original manuscript, to P. Penven (IRD) for making available the ROMS 1D model and for helping for its use, E. Mason (ULPGC) for his corrections on the manuscript and S. Hernández-León for his comments on the zooplankton cycle.

NOAA-ESRL Physical Sciences Division, the ECMWF and the WHOI are acknowledged for providing the data sets used in the forcing, and the NODC for making available the World Ocean Atlas.

Funding by Fonds de la Recherche Scientifique - FNRS through a FRIA Grant and by the MEC through RODA Project (CMT2004-06842-CO3/MAR) are greatly appreciated. This research was initialized during a stay of $\mathrm{C}$. Troupin at the ULPGC facilitated by an ERASMUS grant from the European Commission.

This is MARE publication 172.

\section{References}

Arístegui, J., Hernández-León, S., Montero, M. F., Gómez, M., 2001. The seasonal planktonic cycle in coastal waters of the Canary Islands. Sci. Mar. 65, 51-58.

Arístegui, J., Montero, M. F., 2005. Temporal and spatial changes in plankton respiration and biomass in the Canary Islands region: the effect of mesoscale variability. J. Mar. Syst. 54, 65-82.

Arístegui, J., Sangrà, P., Hernández-León, S., Cantón, M., Hernández-Guerra, A., Kerling, J. L., 1994. Islandinduced eddies in the Canary Islands. Deep-Sea Res. 41, 1509-1525.

Arístegui, J., Tett, P., Hernández-Guerra, A., Basterretxea, G., Montero, M. F., Wild, K., Sangrà, P., HernándezLeón, S., Cantón, M., García-Braun, J., Pacheco, M., Barton, E. D., 1997. The influence of island-generated eddies on chlorophyll distribution: a study of mesoscale variation around Gran Canaria. Deep-Sea Res. 44, 71-96.

Bahamón, N., Cruzado, A., 2003. Modelling nitrogen fluxes in oligotrophic environments: NW Mediterranean and NE Atlantic. Ecological Modelling 163, 223-244.

Barton, E. D., Arístegui, J., Tett, P., Cantón, M., GarcíaBraun, J., Hernández-León, S., Nykjaer, L., Almeida, C., Almunia, J., Ballesteros, S., et al., 1998. The transition zone of the Canary Current upwelling region. Prog. Oceanogr. 41, 455-504.

Barton, E. D., Arístegui, J., Tett, P., Pérez, E. N., 2004. Variability in the Canary Islands area of filament-eddy exchanges. Prog. Oceanogr. 62, 71-94.
Barton, E. D., Basterretxea, G., Flament, P., MitchelsonJacob, E. G., Jones, B., Arístegui, J., Felix, H., 2000. Lee region of Gran Canaria. J. Geophys. Res. 105, 1717317193.

Barton, E. D., Flament, P., Dodds, H., Mitchelson-Jacob, E. G., 2001. Mesoscale structures viewed by SAR and AVHRR near the Canary Islands. Sci. Mar. 65, 167-175.

Braun, J. G., 1976. Production Studies in Canary Islands waters. I. Hydrography, nutrients and primary production.

Brochier, T., Mason, E., Sangrà, P., Lett, C., 2008. Ichthyoplankton transport from the african coast to the canary islands: a case study using a high-resolution hydrodynamic. In: Science and the Challenge of Managing Small Pelagic Fisheries on Shared Stocks in Northwest Africa. Casablanca, Morroco.

Dadou, I., Lamy, F., Rabouille, C., Ruiz-Pino, D., Andersen, V., Bianchi, M., GarÃßon, V., 2001. An integrated biological pump model from the euphotic zone to the sediment: a 1-D application in the Northeast tropical Atlantic. Deep-Sea Res. 48, 2345-2381.

Davenport, R., Neuer, S., Helmke, P., Pérez-Marrero, J., Llinás, O., 2002. Primary productivity in the northern Canary Islands region as inferred from SeaWiFS imagery. Deep-Sea Res. 49, 3481-3496.

de Boyer Montgut, C., Madec, G., Fischer, A. S., Lazar, A., Iudicone, D., 2004. Mixed layer depth over the global ocean: An examination of profile data and a profil-based climatology. J. Geophys. Res. 109, C12003.

De León, A. R., Braun, J. G., 1973. Ciclo anual de la producción primaria y su relación con los nutrientes en aguas canarias. Bol. Inst. Esp. Ocean. 167, 1-24.

Drange, H., 1996. A 3-dimensional isopycnic coordinate model of the seasonal cycling of carbon and nitrogen in the Atlantic Ocean. Phys. Chem. Earth 21, 503-509.

Dugdale, R. C., Goering, J. J., 1967. Uptake of new and regenerated forms of nitrogen in primary production. Limnol. Oceanogr. 12, 196-206.

Fasham, M. J. R., Ducklow, H. W., McKelvie, S. M., 1990. A nitrogen-based model of plankton dynamics in the oceanic mixed layer. J. Geophys. Res. 48, 591-639.

Frentzel, H., 2006. The biogeochemical model of the Regional Ocean Modeling System (ROMS). Available online http://www.brest.ird.fr/Roms_tools.

Garcia, H. E., Locarnini, R. A., Boyer, T. P., Antonov, J. I., 2006a. World Ocean Atlas 2005, Volume 3: Dissolved oxygen, apparent oxygen utilization, and oxygen saturation. Tech. rep., NOAA, Washington D.C., 342pp.

Garcia, H. E., Locarnini, R. A., Boyer, T. P., Antonov, J. I., 2006b. World Ocean Atlas 2005, Volume 4: Nutrients (phosphate, nitrate, silicate). 396pp.

Garwood, R. W., 1977. An oceanic mixed layer model capable of simulating cyclic states. J. Phys. Oceanogr. 7, $455-471$.

Gruber, N., Frenzel, H., Doney, S. C., Marchesiello, P., McWilliams, J. C., Moisan, J. R., Oram, J. J., Plattner, G.-K., Stolzenbach, K. D., 2006. Eddy-resolving simu- 
lation of plankton ecosystem dynamics in the california current system. Deep-Sea Research 53, 1483-1516.

Haney, R. L., 1971. Surface thermal boundary conditions for ocean circulation models. J. Phys. Oceanogr. 1, 241248.

Harris, R., Wiebe, P., Lenz, J., Skjoldal, H.-R., Huntley, M. E., 2000. Zooplankton Methodology Manual. Academic Press, London, UK.

Hernández-León, S., Almeida, C., Bécognée, P., Yebra, L., Arístegui, J., 2004. Zooplankton biomass and indices of grazing and metabolism during a late winter bloom in subtropical waters. Mar. Biol. 145, 1191-1200.

Hernández-León, S., Gómez, M., Arístegui, J., 2007. Mesozooplankton in the Canary Current System: The coastalocean transition zone. Prog. Oceanogr. 74, 397-421.

Hernández-León, S., Llinás, O., Braun, J. G., 1984. Ciclo anual de la biomasa del mesozooplancton sobre un area de plataforma en aguas del Archipielago Canario. Inv. Pesc. 52, 3-16.

Hernández-León, S., Llinás, O., Braun, J. G., 1984. Nota sobre la variación de la biomasa del mesozooplancton en aguas de Canarias. Inv. Pesc. 48, 495-508.

Jackett, D. R., McDougall, T. J., 1995. Minimal adjustment of hydrostatic profiles to achieve static stability. J. Atmos. Ocean. Tech. 12, 381-389.

Kanamitsu, M., Ebisuzaki, W., Woollen, J., Yang, S.-K., Hnilo, J. J., Fiorino, M., Potter, G. L., 2002. NCEP-DOE AMIP-II Reanalysis (R-2). Bul. of the Atmos. Met. Soc. 83, 1631-1643.

Kara, A. B., Rochford, P. A., Hurlburt, H. E., 2000. An optimal definition for ocean mixed layer depth. J. Geophys. Res. 105, 16803-16821.

Killworth, P. D., Smeed, D. A., Nurser, A. J. G., 2000. The effects on ocean models of relaxation toward observations at the surface. J. Phys. Oceanogr. 30, 160-174.

Large, W. G., McWilliams, J. C., Doney, S. C., 1994. Oceanic vertical mixing: a review and a model with a nonlocal boundary layer parameterization. Rev. Geophys. $32,363-403$.

Locarnini, R. A., Mishonov, A. V., Antonov, J. I., Boyer, T. P., Garcia, H. E., 2006. World Ocean Atlas 2005, Volume 1: Temperature. Tech. rep., NOAA, Washington D.C., $182 \mathrm{pp}$.

Mason, E., Colas, F., Molemaker, J., Shchepetkin, A., Sangrà, P., McWilliams, J. C., 2008a. Seasonal variability of the canary current system. In: Eastern Boundary Upwelling Ecosystems. Las Palmas de Gran Canaria, Spain.

Mason, E., Sangrà, P., Colas, F., Molemaker, J., Shchepetkin, A., Hughes, M., Dong, C., McWilliams, J. C., 2008b. A high resolution numerical model study at the Canary islands. In: Ocean Science Meeting. Orlando, USA.

Mellor, G. L., Yamada, T., 1974. A hierarchy of turbulence closure models for planetary boundary layers. J. Atmos. Sci. 31, 1791-1806.

Neuer, S., Cianca, A., Helmke, P., Freudenthal, T., Davenport, R., Meggers, H., Knoll, M., Santana-Casiano, J. M.,
González-Dávila, M., Rueda, M.-J., et al., 2007. Biogeochemistry and hydrography in the eastern subtropical North Atlantic gyre. Results from the European timeseries station ESTOC. Prog. Oceanogr. 72, 1-29.

Niiler, P. P., Kraus, E. B., 1977. Modelling and Prediction of the Upper Layers of the Ocean. Oxford: Pergamon Press, New York.

Nybakken, J. W., 2001. Marine Biology, An Ecological Approach. Benjamin Cummings, San Francisco.

Pelegrí, J. L., Arístegui, J., Cana, L., González-Dávila, M., Hernández-Guerra, A., Hernández-León, S., MarreroDíaz, A., Montero, M., Sangrà, P., Santana-Casiano, M., 2005a. Coupling between the open ocean and the coastal upwelling region off northwest Africa: water recirculation and offshore pumping of organic matter. J. Mar. Syst. $54,3-37$.

Pelegrí, J. L., Marrero-Díaz, A., Ratsimandresy, A., Antoranz, A., Cisneros-Aguirre, J., Gordo, C., Grisola, D., Hernández-Guerra, A., Laíz, I., Martínez, A., Parrilla, G., Pérez-Rodríguez, P., Rodríguez-Santana, A., Sangrà, P., 2005b. Hydrographic cruises off northwest Africa: the Canary current and the Cape Ghir region. J. Mar. Syst. 54, 39-63.

Penven, P., 2006. 1D ROMS model documentation. Available online http://www.brest.ird.fr/Roms_tools/roms1d.

Pérez, F. F., Mintrop, L., Llinás, O., González-Dávila, M., Castro, C. G., Alvarez, M., Körtzinger, A., SantanaCasiano, M., Rueda, M. J., Ríos, A. F., 2001. Mixing analysis of nutrients, oxygen and inorganic carbon in the Canary Islands region. J. Mar. Syst. 28, 183-201.

Price, J. F., Weller, R. F., Pinkel, R., 1986. Diurnal cycling: Observations and models of the upper ocean response to diurnal heating, cooling and wind mixing. J. Geophys. Res. 91, 8411-8427.

Redfield, A. C., 1934. On the proportions of organic derivations in sea water and their relation to the composition of plankton. In: Daniel, R. (Ed.), James Johnson Memorial Volume. University Press of Liverpool, pp. 177-192.

Reynolds, R. W., Rayner, N. A., Smith, T. M., Stokes, D. C., Wang, W., 2002. An improved in situ and satellite SST analysis for climate. J. Clim. 15, 1609-1625.

Sarmiento, J. L., Slater, R. D., Fasham, M. J. R., Ducklow, H. W., Toggweiler, J. R., Evans, G. T., 1993. A seasonal three-dimensional ecosystem model of nitrogen cycling in the North Atlantic euphotic zone. Global Biogeochem. Cycles 7, 417-450.

Shchepetkin, A. F., McWilliams, J. C., 2005. The regional oceanic modeling system (ROMS): a split-explicit, freesurface, topography-following-coordinate oceanic model. Ocean Modell. 9, 347-404.

Sverdrup, H. U., 1953. On conditions for the vernal blooming of phytoplankton. J. Cons. Perm. Int. Explor. Mer. 18, 287-295.

Tett, P., Arístegui, J., Barton, D., Basterretxea, G., Armas, J. D. D., Escánez, J. E., Hernández-León, S., Lorenzo, L. M., Montero, N., 2002. Steady-state DCM dynamics 
in Canaries waters. Deep-Sea Res. 49, 3543-3559.

Uppala, S. M., Kallberg, P. W., Simmons, A. J., Andrae, U., da Costa Bechtold, V., Fiorino, M., Gibson, J. K., Haseler, J., Hernandez, A., Kelly, G. A., et al., 2005. The ERA-40 re-analysis. Quart. J. R. Meteorol. Soc. 131, 2961-3012.

Yu, L., Weller, R. A., 2007. Objectively analyzed air-sea heat fluxes for the global ice-free oceans (1981-2005). Bull. Am. Meteorol. Soc. 88, 527-539.

Yu, L., Weller, R. A., Sun, B., 2004. Improving latent and sensible heat flux estimates for the Atlantic Ocean (19881999) by a synthesis approach. J. Clim. 17, 373-393.

Zhang, Y.-C., Rossow, W. B., Lacis, A. A., Oinas, V., Mishchenko, M. I., 2004. Calculation of radiative fluxes from the surface to top of atmosphere based on ISCCP and other global data sets: Refinements of the radiative transfer model and the input data. J. Geophys. Res. 109, D19105.

Zielinski, O., Llinás, O., Oschlies, A., Reuter, R., 2002. Underwater light field and its effect on a one-dimensional ecosystem model at station ESTOC, north of the Canary Islands. Deep-Sea Res. 49, 3529-3542. 